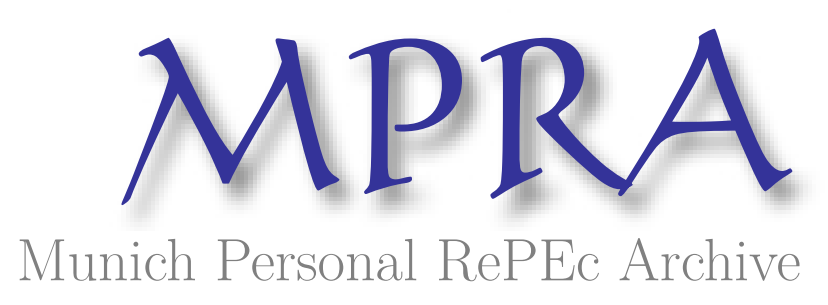

\title{
The urban component of the energy crisis
}

Pareto, Vittorio Emmanuel and Pareto, Marcos Pompeu

2008

Online at https://mpra.ub.uni-muenchen.de/13989/

MPRA Paper No. 13989, posted 13 Mar 2009 06:17 UTC 


\title{
The Urban Component of the Energy Crisis
}

\author{
Vittorio E. Pareto, Ph.D. \\ Marcos P. Pareto
}

August 2008 


\section{Abstract}

The spiral of higher oil prices that is occurring currently is mostly caused not by the lack of reserves, but by increasing demand on the existing supply. However, increase of supply would only temporarily attenuate the issue, as demand is expected to continue to soar and eventually outstrip the reserves of fossil fuels, which combined account of almost all our present energy sources. It is not that fossil fuels will disappear, but rather the certainty that they will become progressively scarcer and definitely more expensive as time goes by, has become an irreversible and well established trend.

The cost increase of a critical resource - energy - will force unforeseen changes in production and in distribution of goods, affecting the whole productive matrix - including employment. Not only new products and distribution systems based on higher energy costs will need to be conceived and implemented but especially the current reliance on fossil fuels - oil, gas and coal - will need to be replaced almost entirely by sustainable sources - an extraordinarily complex enterprise that should consume our efforts in the next 40 years.

Energy consumption will be further aggravated by the expected 2.3 billion population increase from now to 2050, which is expected to be almost entirely concentrated in the urban centres of Asia, Latin America and Africa. Since these additional urban spaces are still to be developed, urban development strategies that consider higher energy costs could effectively alleviate the transition period from fossil fuels to sustainable sources.

Rather than providing a recipe for urban planning, this paper stresses the need for further research to incorporate the energy cost component with the urban development context and the dissemination of information on this matter. 


\section{Introduction}

Among the current financial and economic crisis, and sometimes thought to be derived from it, a fundamental change is taking place, caused by the unsustainability of the current production and transportation systems, which were developed based on the easy availability of cheap fossil fuels. The current abrupt increase of fuel prices is not a result of a conjunctural event but a dramatic symptom of a failing supply of energy. Cheap energy was one of the main factors that allowed the explosive economic development that occurred during the last century, especially since the end of the WWII. Unfortunately, that phase seems to be over. To maintain the world development process, a new balance has to be found between the new production and distribution profiles, taking into account the energy factor. This is a normal event in the development process yet in this case will affect almost all the productive system simultaneously and our consumption habits at an extremely fast pace. It is the speed of change the real issue we have to cope with.

This paper intends to discuss the main factors of the energy crisis, why it is happening now and how urban development planning can contribute to alleviate the transition period. Rather than being conclusive, it proposes some lines of research that should be explored in the near future to support urban planning and development, adding the energy aspect to the conventional physical, economic and social components of urban planning.

\section{The Energy Supply Issue}

The world reserves of raw materials are the total amount of these materials that are physically, technically and economically available under present conditions, i.e. that can be placed in the market at the current price structure. Under these criteria, the total world reserves of fossil fuels are assumed to be around 180 billion TCE ${ }^{1}$ of natural gas, 300 billion TCE of mineral oil, shale and liquid gas, and 600 billion TCE of coal (all forms), adding up to the impressive amount of 1,100 billion TCE. On the other side is the world's consumption rate, which is currently around 14 billion TCE (RWE World Energy Report 2005). In other words, if consumption remains at the same level (no economic development - no population growth scenario), the present reserves would be enough to last almost until the end of this century at the current prices.

\footnotetext{
${ }^{1}$ TCE - tonne of coal equivalent. Energy generated by burning 1 metric ton of coal, equivalent to the energy obtained by burning 5.2 barrels of oil $(700 \mathrm{~kg}), 890 \mathrm{~m}^{3}$ of natural gas ( 27.8 million BTU) or $8.14 \mathrm{MWh}$.
} 
Oil, gas and coal - which together provide $87 \%$ of the world's energy - are convenient, powerful and, until now, still cheap to obtain. All other forms of generating energy - from nuclear to hydro, solar, wind and others do not weight much on global terms. More precisely, oil accounts for $38 \%$, gas $23 \%$ and coal $26 \%$ of the world energy consumption. Nuclear and hydro provide only $6 \%$ each, while all other sources combined provide less than $1 \%$. Liquid fuel alternatives such as shale oil, extra-heavy oil, bio-fuels (mainly ethanol and bio-diesel), liquefied coal or gas are expected to become increasingly competitive in the near future, as conventional fuels reach higher price levels. Their supply is expected to grow from 2.5 to 9.7 million barrels per day from 2005 to 2030 . Yet all these alternative sources combined are not expected to account for more than $10 \%$ of the liquid fuel demand in 2030.

The availability of fossil fuels as our main source of energy is limited by technical and economical factors. In principle neither oil, nor gas and coal will ever be physically totally exhausted. Yet as the easier and cheaper options to find and explore are used, extraction costs increase while the amount produced tends to be relatively smaller. For those reasons, reserves of fossil fuels are measured in terms of their economic availability under present conditions (RWE 2005, EIA 2005).

It should mentioned that there are also enormous quantities of "resources", a term given to fossil fuel deposits that are not considered reserves, because they are not feasible to explore under the current price structure. It is clear that some of these resources may eventually become reserves as prices go up and new exploration techniques are developed. Yet one should also consider that deposits with low yield and difficult extraction consume an increasing amount of energy to be transformed into fuel, effectively reducing their net energy content (RWE 2005).

As energy prices increase, lower yield resources are upgraded to economically feasible reserves, even if no new findings are made. The critical point is when the demand equals the production capacity - the "peak". When this happens, higher prices constrain the demand, and simultaneously allow a boost in reserves, inducing an increase in supply until in due course a new peak is attained. As global reserves are used, the inter-peak periods tend to shorten and, if no alternative sources are ready take over, a supply collapse is possible. Such scenario could bring a worldwide fuel shortage of unpredictable consequences. 
Therefore the critical issue is not when the existing reserves of fossil fuels would end - in principle they will continue to be available as prices increase - but the peak. According to some experts, oil has already started to peak (Hubbert, 1956; Deffleyes, 2002). Gas and coal reserves are bigger than oil, so the latter will tend to be progressively replaced by the former, which should attenuate a price explosion. Nevertheless this process will push energy prices higher, until sustainable sources replace our dependency on fossil fuels as major source of energy.

Higher energy prices will make alternative sources of energy economically feasible. Yet two additional issues still have to be considered: first of all, the time lag and the resources needed to tap these alternative sources and bring up production to balance the reduction in supply of fossil fuels. Secondly, the fact that industrial production and transportation costs will by definition be higher, bringing in a possible recessive trend with a consequent drop in living standards until higher performance and efficiency and technological improvements can outweigh the higher production and distribution costs. Secondly, the fact that industrial production and transportation costs will increase as energy costs rise, bringing in a possible recessive trend with a consequent drop in living standards. Such situation may prevail until higher efficiency and technological improvements can outweigh the higher production and distribution costs.

Various apocalyptic scenarios have been built under the assumption of massive shortages of essential resources such as food or energy, ranging from Malthus' population study to the seminal Limits to Growth (Meadows, 1972 and 2004). While significant advances in technology and production efficiency have prevented catastrophic scenarios from happening, their warnings are sobering and cannot be dismissed.

What are the alternatives? Uranium reserves, based on production prices of up to $\$ 40 / \mathrm{kg}$, are only about 40 billion TCE. Yet, contrariwise to fossil fuels, the cost of uranium ore is an insignificant part in the cost of energy produced - only about 0.1 cent/KWh, about $2-3 \%$ of the production cost. It has been estimated that if the price of extraction and concentration reached higher levels - even to the extreme of $\$ 1,000 / \mathrm{kg}$ - the availability of uranium as fuel would become virtually endless while the fuel cost would still remain a minor component of nuclear energy. The use of more advanced reactors and breeder technology can further contribute to lower costs and limit fuel demand (Hopf 2004). 
The energy issue is neither the technology nor the potential availability - the critical issues are the logistic factors required to replace fossil fuels by other sustainable sources within a 40 -year period. Such effort - necessary to avoid a major energy crisis - requires a serious commitment of capital, human resources, industrial organization and last but not least, political will. Estimates indicate that to supply two thirds of the foreseen 2050 demand for energy would require the construction of about two hundred nuclear power plants per year, each taking over five years of construction before becoming productive ${ }^{2}$, although adoption of standard design and equipment could probably shorten the development period and reduce costs. (Murkeheide 2005).

Renewable sources, such as solar, wind power or geo-thermal should become increasingly competitive as energy costs rise and have an endless availability. Yet not only is the current production insignificant, but any massive worldwide conversion to such ecological sustainable sources seems implausible within the available time frame for replacement. Furthermore, the energy from these sources is complementary to energy from conventional plants (uranium, hydro), requires specific conditions to work and is more expensive to implement. Hydroelectric production is expected to increase and share with nuclear and gas-driven plants most of the sources for electric energy in the near future (RWE 2005).

It seems clear that high oil prices will reduce oil consumption and at the same time constrain development, which is one of the main forces pushing higher consumption. At the same time, high oil prices will stimulate the use of alternative and renewable sources. Yet it should be clear that not only is cheap energy from oil gone, but that the time lag until sustainable sources can become significantly productive - such as producing bio-fuels, building hydro-electric dams and nuclear plants - will constrain energy availability for some time, regardless of the scenario considered.

\footnotetext{
${ }^{2}$ Replacing two-thirds of energy production from fossil fuels to other sources by 2050 would require building about 8,000 1.5 MW power plants, at a cost of about 2.5 billion each - regardless of using nuclear, hydro, wind or other sustainable energy source. It is assumed that by 2050 both gas and oil will be too costly to supply the energy demand and the only remaining fossil fuel available would be coal. Although using bio-fuels is possible, their demand for fertile land - required to feed 9 billion people - and the huge quantities involved may limit their use as a major source of energy.
} 


\section{Energy Demand Pattern}

Compounding to supply constraints, the increase in demand aggravates the problem and turns what could be a smooth transition to a more dramatic situation. Demand for energy is driven by two main factors - population growth and economic development. The world's population is estimated to grow from the current 6.9 to 9.2 billion by 2050, adding 2.3 billion people to the planet in just 40 years. This increase is not evenly distributed. The industrialized nations have already stabilized their population at a little over 1.2 billion and all the expected population growth should happen in the developing nations (UN 2007). Similarly, during this same period the rate of economic development is expected to remain low at less than $2 \%$ in the industrialized countries, while the developing nations should maintain a high 4-5\% rate of economic development.

The increase in energy demand is expected to remain almost stable in the developed nations, due to a slower economic development balanced by the use of more efficient equipment. Contrariwise, consumption should increase at an exponential rate in the developing countries. In spite of an increasing price pattern, the world demand for energy is expected to grow by 50\% from 2005-2030, with the non-OECD countries accounting for about $85 \%$ of the additional demand. The total energy consumption of the non-OECD countries should surpass the consumption of the OECD countries as early as 2010 (EIA/IEO 2007). In the cities of Asia, Latin America and Africa, new businesses are continuously being created, generating employment, and millions of people are swapping their bicycles for cars and acquiring more fridges, TVs, air conditioners and all kinds of home appliances, as personal prosperity rises in line with national economic growth (ExxonMobil 2008).

The use of energy is overwhelmingly concentrated in urban areas, where $75 \%$ of the energy consumption takes place, and the urbanization trend remains firm (BP 2008). Until 2050 the world's urban expected to increase dramatically, from 3.5 to 6.4 billion people. Within this context, the cities of the developing nations are expected to double, absorbing 2.7 billion new dwellers ${ }^{3}$, and bringing a correspondingly higher demand for housing, infrastructure, jobs and energy (UN 2007).

As such, it seems clear that while one focus of attention should be on shifting energy production from fossil fuels to sustainable sources, an equally important one is where the increase in demand will take place: in the rapidly expanding urban centres of the developing nations.

\footnotetext{
${ }^{3}$ The urban population of the less developed regions is expected to increase from 2,570 million (2010) to 5,327 (2050) - UN Urbanization Prospects, 2007 Revision Database.
} 


\section{Urban Development Alternatives}

In the developed nations both the urban network and city sizes are almost entirely static. The regional and urban infrastructure is fully developed, limiting the possibility of a significant increase in energy efficiency. Because the possibility of physical change is negligible, improvements are limited to increasing the operational efficiency of the transportation network (both inter and intra-urban) and introducing energy conservation strategies.

Contrariwise, the cities in the developing countries of Asia, Latin America and Africa will double in size in the next forty years to cater for 2.7 billion more people. Such urban places - equalling in size all the currently existing cities put together - present a unique opportunity to consider the energy factor when planning and building the urban spaces. There are four main areas where urban and regional development planning can contribute to improve energy efficiency and avoid waste: the location of cities, the urban size and land use, and building design.

Cities are focal points of economic activities - and this is the main single reason why urban centres develop and grow. The basic reasons for development of urban centres are to be found in the economic activities they perform in the economy and the people directly or indirectly employed by these activities. Urban location theory is based on the distribution of economic activities throughout the geographic space and in the distribution system (Christaller 1966, Lösch 1973, Alonso 1964, Johnson 1975), taking into account the cost of transportation from the production areas to the consumers. Yet the flow of goods that justified the concept of a "central place" hierarchy of urban centres disintegrated in the twentieth century, mostly due to the availability of extremely cheap fuels and the development of modern and efficient means of transportation.

Rather than based on the typology of the urban economic profile, urban centres with higher product developed faster. Economies of scale reinforced the development of primary cities and eventually of mega-cities, with tens of millions inhabitants and attaining economic self-sufficiency regardless of their geographical location. Larger cities and metropolises mostly arise because of economies of scale, especially when the availability of human resources and of essential supporting services is essential to compete in the world market. As investments increase, more resources flow in and the more attractive is the city for further investments, which in turn generates employment and attracts migrants. 
This cycle is especially visible in the developing countries, where such resources are scarce and are frequently limited to a few centres, reinforcing the primacy paradigm. Yet the continuous expansion of city sizes does not come without a price - diseconomies of scale such as congestion, failing urban transportation, poor quality of life, pollution, higher land prices and lack of infrastructure - not to mention higher social dysfunctions such as criminality and loss of social order - can erode some of the advantages of the larger centres in favour of alternative locations (Royuela \& Suriñach, 2005). Furthermore, the relative loss of importance of geographic location in urban development may need to be reconsidered as transportation costs increase, restoring some of the original assumptions of the location theory.

Another issue of larger cities is that their higher affluence level acts as a magnet, generating strong migration flows from smaller centres and urban areas, where employment if limited, income levels are lower and opportunities are scarcer (Harris \& Todaro, 1970). Indeed, the development of urban economic activities often benefits from the labour of migrants. Yet while providing mutual economic advantages, excessively fast migration flows tend to overburden urban services and to generate widespread informal settlements and squatters. Most local government policies try to alleviate such problems by improving urban conditions: expanding the infrastructure and services networks and incorporating more space to cater for future urban growth. Yet such measures may eventually aggravate the problem of excessive urban size and continuous growth.

Urban energy consumption profiles can vary widely. Taking four large Asian cities - Tokyo, Seoul, Beijing and Shanghai - the amount of energy consumed by industrial activities can range from $80 \%$ in Shanghai to only $11 \%$ in Tokyo, while residential consumption can vary from $37 \%$ in Seoul) to only $7 \%$ in Shanghai). Beijing consumes only $8 \%$ of its energy in transportation, in contrast with $37 \%$ in Tokyo; and while Shanghai commercial activities consume 3\% of its energy, Tokyo consumes $30 \%$, ten times as much (Doi 2005). It becomes clear that a range of other factors can influence the energy consumption profile, such as the prevailing economic system and urban affluence, in addition to the level of development and typology of economic activities performed.

Urban transport is one of the major components in the consumption of energy. It is evident that on average distances increase as the area of the city expands - and longer distances will necessarily consume more energy. Furthermore, a road system designed when the city was much smaller and transportation needs more limited cannot cope with the traffic generated when it grows to a size several times larger. Enlarging main roads or building elevated highways is sometimes possible, yet 
at the cost of poorer urban quality. Furthermore, as the number of vehicles increases it becomes virtually impossible to expand road sizes at surface level - not mentioning the issue of providing parking spaces. If roads could keep increasing in size according to traffic demands, eventually all the city centre would have to be demolished to make a giant roundabout. To cope with increasing demand for personal transportation, especially the critical home-to-work peak, the favoured solution has been to promote the use of public transport and adopt mass transit solutions, like underground rail systems. Yet those systems are expensive to build and operate, and do not provide more than a temporary relief from congestion. Eventually there is a point of utter collapse, as some megalopolises have already reached.

There is a vast demand for energy ready to explode in the cities of the developing countries. Increasing the efficiency of land use design to reduce the demand to travel long distances and stimulating neighbourhood activities and non-motorized traffic (walkways, bicycles, etc) can result in massive savings in energy use. It has been demonstrated that it is possible to have pedestrian cities that can support more than 100,000 people without incurring excessive densities, limiting green areas or lowering the quality of live. Such settlements do not need to eradicate personal vehicles the car is also a cherished symbol of freedom besides providing personal comfort. The point is that by making the personal car an option rather than a necessity, it is feasible to have better cities without sacrificing quality of life or the freedom of movement.

Larger cities could be designed combining such "urban modules", without significantly changing the concept. Cities much larger than one million could be avoided altogether - there are very few economic activities that need a supporting population of over a million people. Yet even larger urban conglomerations can be conceived by establishing an urban network, much like the Swiss or Dutch model. Such type of urban structure could provide a concentration of urban dwellers spread throughout a relatively small geographic space, thus providing the benefits of a large concentration of economic activities and resources - taking full advantage of economies of scale without incurring in excessive congestion, pollution, long commuting periods or high transportation costs.

Such urban development strategy could be adopted in the developing countries, providing not only significant savings in intra-urban transport but also in inter-urban transportation, focusing on a more energy efficient mode such as rail instead of the current TIR-based inter-urban transportation network. 
Finally, the building structure can play a significant part in avoiding energy wastage by stimulating environmentally efficient design. Except in a few places that have a year-round fair climate - such as Brasilia or Nairobi - in most cities there is need for heating in the winter or cooling in the summer, and sometimes both. By using the proper building materials, insulation and orientation of openings significant energy savings can be attained without sacrificing comfort.

\section{Conclusions}

It seems clear that we are already facing a major crisis in the supply of energy and that the economic production model based on cheap energy needs to be revised. Whatever alternative and sustainable source of energy is preferred, and most probably all means feasibly available will need to be considered, the world economy may have to go through a scarce energy period, in which not only energy will be increasingly expensive, but also difficult to get. To reduce this pressure, not only alternative fuels and other energy sources need to replace current fossil fuels as main sources of energy, but attention should also focus on reducing the growth of demand, by applying technological improvements aiming at higher energy efficiency and through urban development approaches considering the expensive energy situation.

Urban areas - and particularly those that will be built in the developing countries - will account for most of the additional demand for energy in the next 40 years, absorbing 2.7 billion people and almost doubling the demand for energy. Those urban centres present a unique opportunity to apply alternative planning approaches considering location, size and land use decisions under a more expensive energy context. Similarly, the need to build half a billion new housing units, not including replacements, industrial and commercial buildings - a sizable investment in any count - will also present a major opportunity to implement energy-saving design concepts and building techniques to provide environmental comfort and reduce operational costs. These are unique opportunities because the size of urban population is bound to peak in this century and thus the intensity of urban development expected in this first half of the century is not expected to ever repeat itself.

Within this context, accessibility should play a decisive role in location decisions: possibly stimulating more concentrated and economically integrated settlements, or avoiding mega cities in favour of more comprehensive system of urban centres. Such shift in focus could change dramatically the urban sprawl model, bringing striking repercussions in the real estate market (WSJ 2008). 
While the market mechanisms will quickly change energy consumption habits and support a shift toward more energy efficient buildings, a massive effort still needs to be made in disseminating such design methods and building techniques, to ensure that the opportunity will not be missed by ignorance. The revision of building codes is a necessary step in this direction although insufficient by itself.

On the other hand, urban development decisions on expanding existing cities, building new urban centres and setting up urban infrastructure and services according to a preferred land use pattern are made by the local, regional or central authorities, who still are not fully aware of their responsibility in participating in the energy management effort.

To be sure, there is no new urban development approach - an urban development "recipe" considering the energy issue - that is readily available and just needs to be disseminated. A significant effort in research and development should be made to review the theoretical base of urban development, combining the traditional social, cultural, economic and environmental aspects with the increasing importance of dealing with energy demand issue - a task that should be undertaken primarily by universities, research centres and practitioners in the field. 


\section{Sources and References:}

Alonso, W. Location and Land Use. Harvard University Press, 1964.

British Petroleum. "Imperial College Urban Energy Project, 2008." http://www.bp.com

Christaller, W. Central Places in Southern Germany. Prentice Hall, 1966.

Deffeyes, Kenneth. Hubbert's Peak. Princeton University Press, Princeton, NJ, 2002.

Doi, Naoko. "Urban Development and Transportation Energy Demand." Asia Pacific Research Centre, 2005.

Energy Information Administration. "International Energy Outlook - 2008".

http://www.eia.doe.gov/eia

Energy Information Administration. "International Energy Annual - 2005”.

ExxonMobil. "Energy Outlook", 2008. http://www.exxonmobil.com

Harris J. and M. Todaro. Migration, Unemployment \& Development: A Two-Sector Analysis. American Economic Review, March 1970.

Forrester, J. World Dynamics. Wright Allen Press, 1971.

Hopf, James. "World Uranium Reserves - 2004". http://www.americanergyindependence.com

Hubbert, M. King. "Nuclear energy and the fossil fuels." Shell publication \#95. June 1956.

Johnson, E.A. The Organization of Space in Developing Countries. Harvard University Press. 1975.

Karp. J. “Cities lure some US residents from afar.” Wall Street Journal, 18 June 2008, pg 14.

Lahart, J. “Have US drivers reached filling point of no return?" Wall Street Journal, 18 June 2008, pg 14.

Lösch, A. The Economics of Location, Yale University Press, 1973.

Meadows et al. The Limits of Growth, A Report to the Club of Rome. Universe Books, 1979; and The Limits of Growth: the 30-year update. Chelsea Green Publishing, 2004.

Muckerheide, J. "How to build 6,000 Nuclear Plants by 2050". Executive Intelligence Review, June 2005. http://www.larouchepub.com/other/2005/3225build 6000 nukes.html

Royuela, V. and Suriñach. J. "Quality of life and urban size". European Regional Science Association conference papers, 2005.

RWE AG - “World Energy Report - 2005." http://www.rwe.com

Safirova, E. et al. "Spatial development and Energy Consumption" (discussion paper). Resources for the Future, Dec 2007.

UN Population Division, "World Population Prospects: The 2007 Revision and World Urbanization Prospects". http://esa.un.org/unpp and http://esa.un.org/unup 